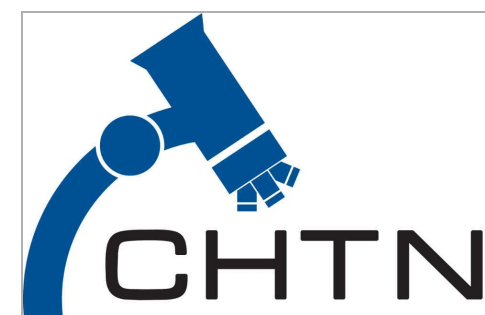

CDDPERATIVE

HUMAN TISSUE NETWDRK

FEB 18, 2021

\section{open Access}

\section{DOI:}

dx.doi.org/10.17504/protocol s.io.6y9hfz6

\section{Protocol Citation: Kerry}

Wiles 2021. Tissue

Procurement: Normal Colon . protocols.io

https://dx.doi.org/10.17504/p rotocols.io.6y9hfz6

License: This is an open access protocol distributed under the terms of the Creative Commons Attribution License, which permits unrestricted use, distribution, and reproduction in any medium, provided the original author and source are credited

\section{Protocol status: Working} We use this protocol and it's working

Created: Aug 30, 2019

Last Modified: Feb 18, 2021

PROTOCOL integer ID: 27393

\section{(3) Tissue Procurement: Normal Colon}

\author{
Kerry Wiles ${ }^{1}$ \\ ${ }^{1}$ Cooperative Human Tissue Network Western Division at Vanderbilt \\ University Medical Center
}

Laboratory of Systems Pharmacology NCIHTAN

\section{Madison Tyler}

Laboratory of Systems Pharmacology

\section{ABSTRACT}

Tissues are procured from a variety of different anatomic sites, each with their own unique qualities to be considered during collection. Anatomic site-specific standard operating procedures (SOPs) are required to address these unique qualities and assist with investigator-specific requests. This protocol for the collection of normal (NL) colon applies for normal adjacent tissue (NAT) in cancerous colons and also for histologically normal diverticulitis colon tissue.

\section{BEFORE START INSTRUCTIONS}

\section{Reference to other CHTN SOPS or Policies}

- Tissue Procurement: Cryopreservation with OCT Compound (dx.doi.org/10.17504/protocols.io.6y7hfzn)

- Tissue Procurement: Fixation with $10 \%$ NBF (dx.doi.org/10.17504/protocols.io.6y4hfyw)

\title{
Tissue Procurement: Normal Colon
}

1 Identify the tissue to be collected in the surgical pathology laboratory. Note that this protocol for 
collection of normal (NL) colon applies for normal adjacent tissue (NAT) in cancerous colons and also for histologically normal diverticulitis colon tissue.

2 The length of colon should be opened and properly cleaned of withheld matter by a resident pathologist or PA before collection of tissue. Note that colon specimens are often very large and often require relatively small amounts of tissue for diagnostic purposes. For these two reasons, it is not atypical to be able to collect large amounts of normal colon tissue.

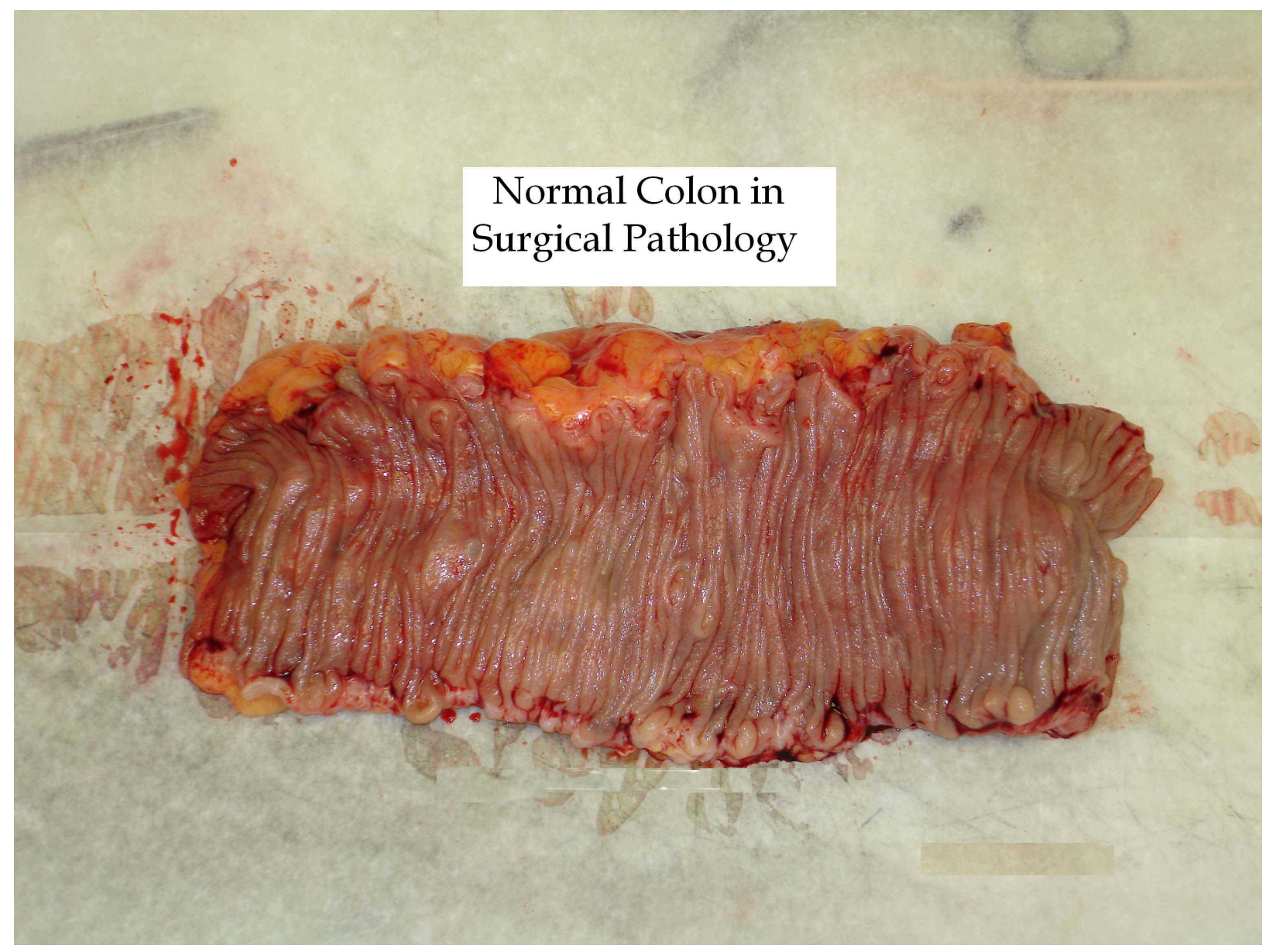

Figure 1. Normal colon in surgical pathology. Omental adipose tissue (top) surrounds mucosal surface (overlying the muscularis).

3 The section of colon taken should exhibit both the mucosa and the muscularis, should be large enough to yield tissue for all desired methods of collection (snap-frozen in liquid nitrogen, frozen in OCT, fixation in paraffin, fresh shipping, etc.), should be free of significant necrosis, and (if NAT) be free of all non-normal tissue (Figure 2, Figure 3). 


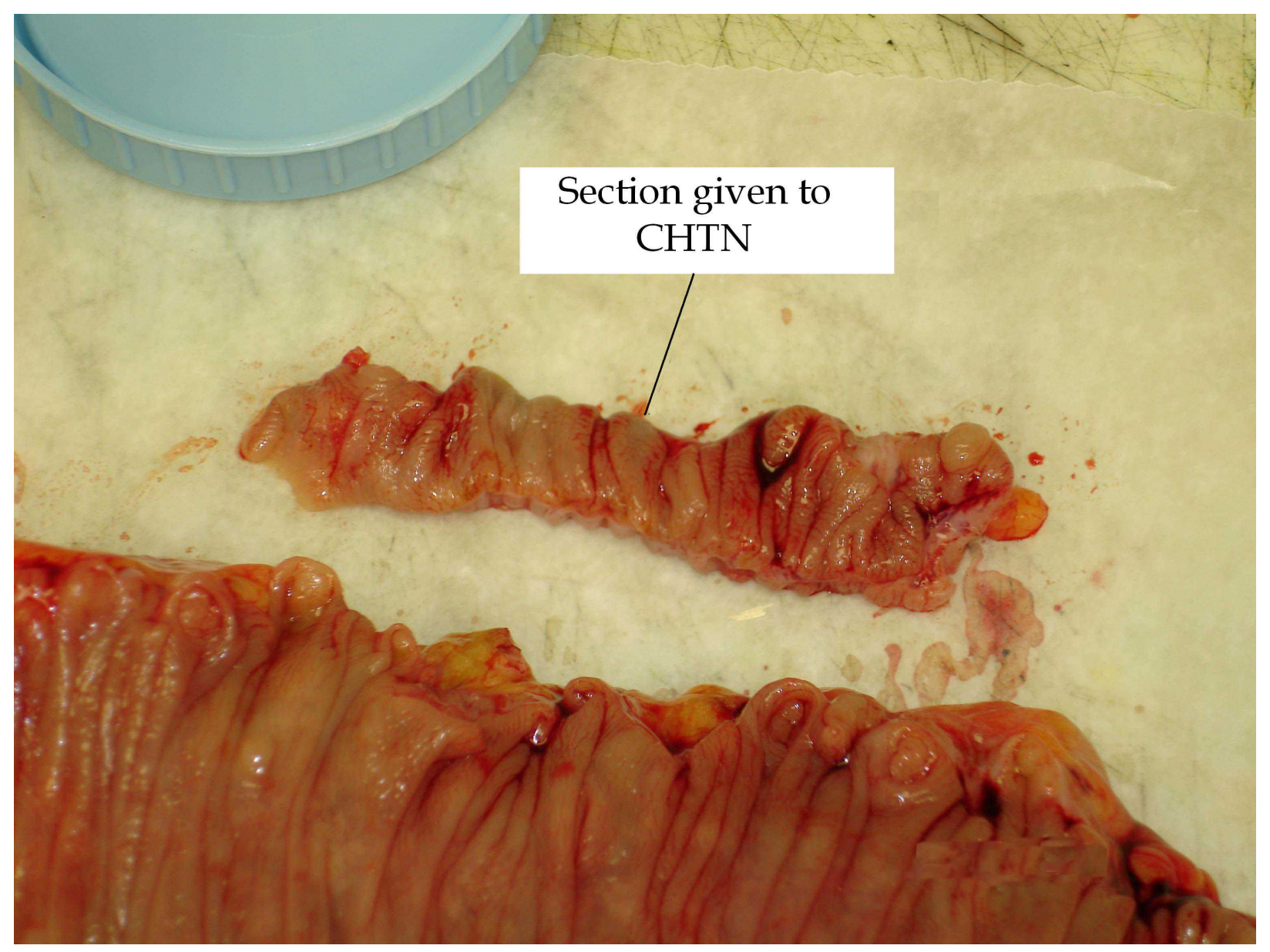

Figure 2. Tissue section given to $\mathrm{CHTN}$.

4 Once the tissue has been procured and transported to the CHTN laboratory, it can then be prepared for preservation. Colon samples will often have visible fat attached, which should be (unless otherwise requested) trimmed off and disposed of. Note the differentiation between the internal mucosa and the external muscle layer, the muscularis. 


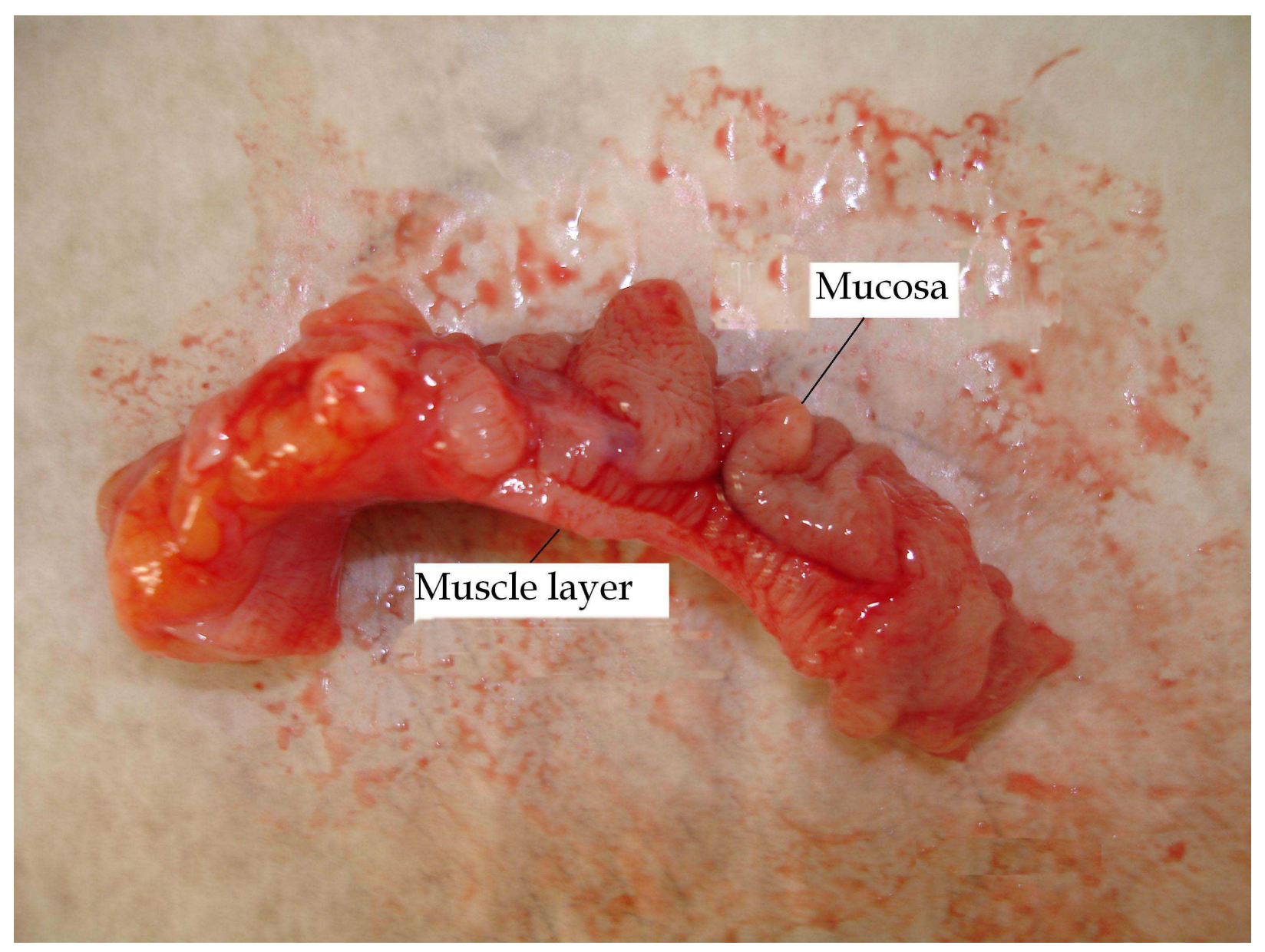

Figure 3. Muscle layer and mucosa of tissue section given to $\mathrm{CHTN}$.

5 Before portioning out the tissue, make sure to cut away a small QA section, which should be excised from the center of the colon sample, should represent both the mucosa and the muscularis, and should also be free of adipose tissue. 


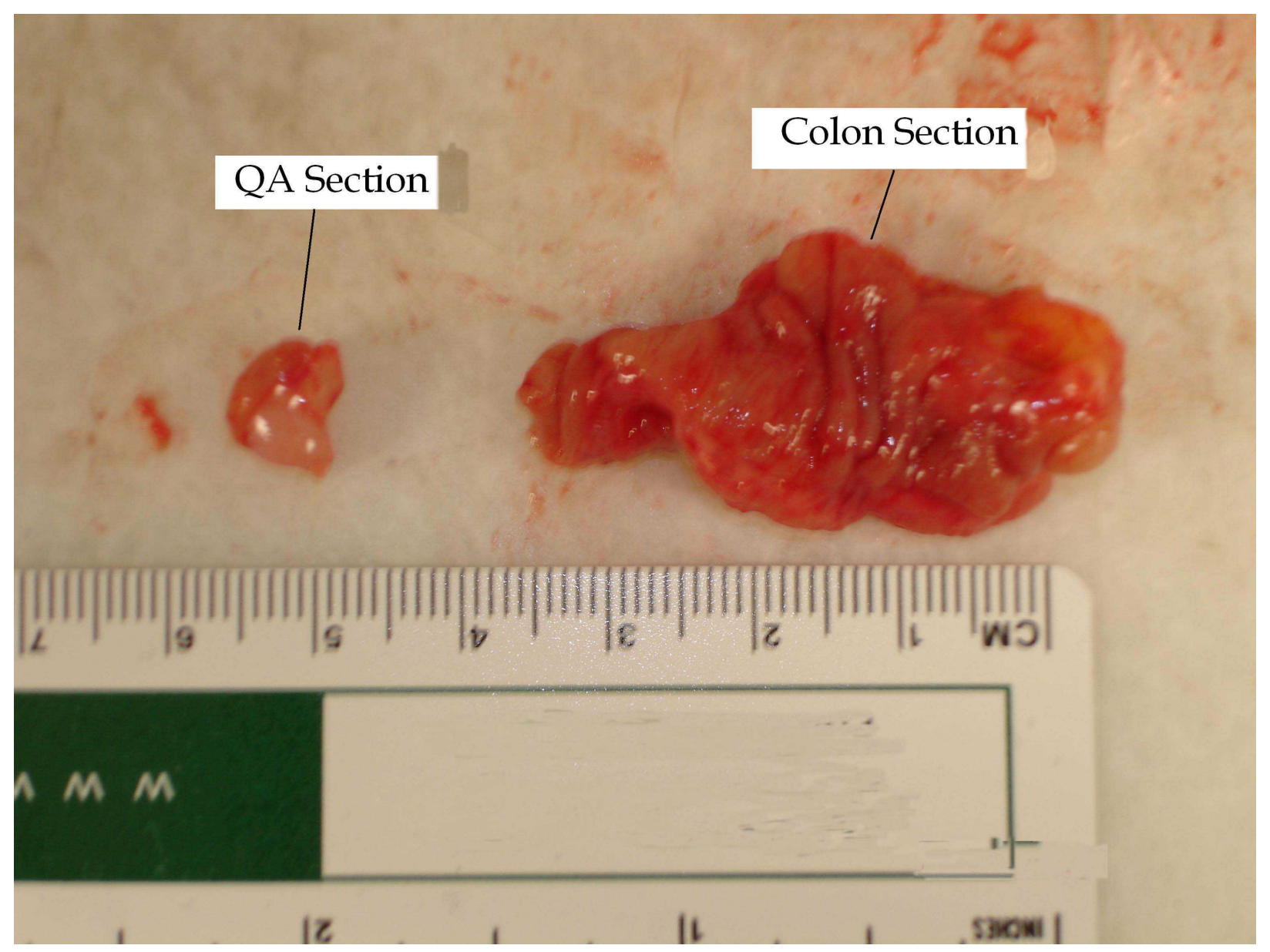

Figure 4. Cut away a small QA section before portioning out the colon section.

6 Utilize the CHTN databases in determining how the collected tissue should be portioned out (i.e. what dimensions, weights, collection methods, etc.), in order to serve CHTN's investigators most efficiently and effectively.

7 Unless other specifications take priority, normal colon should generally be divided up into equal numbers of paraffin blocks, frozen OCT samples, snap-frozen full-cut samples (i.e. displaying both mucosa and muscularis), and snap-frozen mucosa-only samples. Note: If using NAT colon, be sure to cut away any inked tissue before preservation.

8 To produce mucosa-only samples, shear a short length of the lining away from the muscularis using dissection scissors or a razor blade-a delicate but achievable process. 


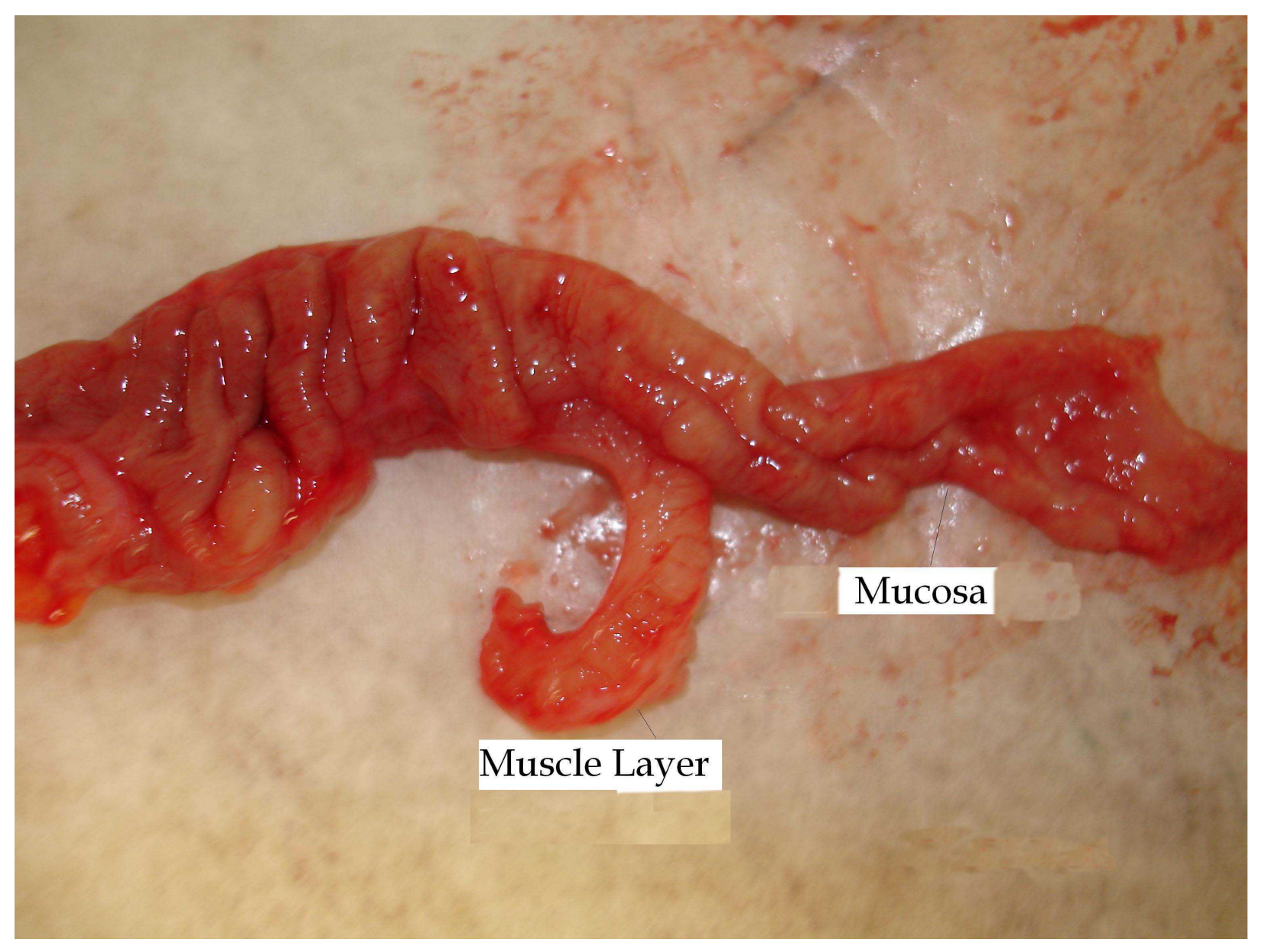

Figure 5. Shear mucosa away from muscularis using dissection scissors or a razor blade.

9 While snap-frozen samples of full-cut colon should weigh $\sim 0.25 \mathrm{~g}$, it may be difficult to consistently produce $\sim 0.25 \mathrm{~g}$ snap-frozen samples of mucosa-only colon. Those clamshells that only contain mucosa should be labeled as such. If no indication is made, then it is assumed that the clamshell contains a full-cut colon sample. Additionally, when it applies, include "mucosaonly" in the descriptors of the tissue acquisition page of the CHTN database. 


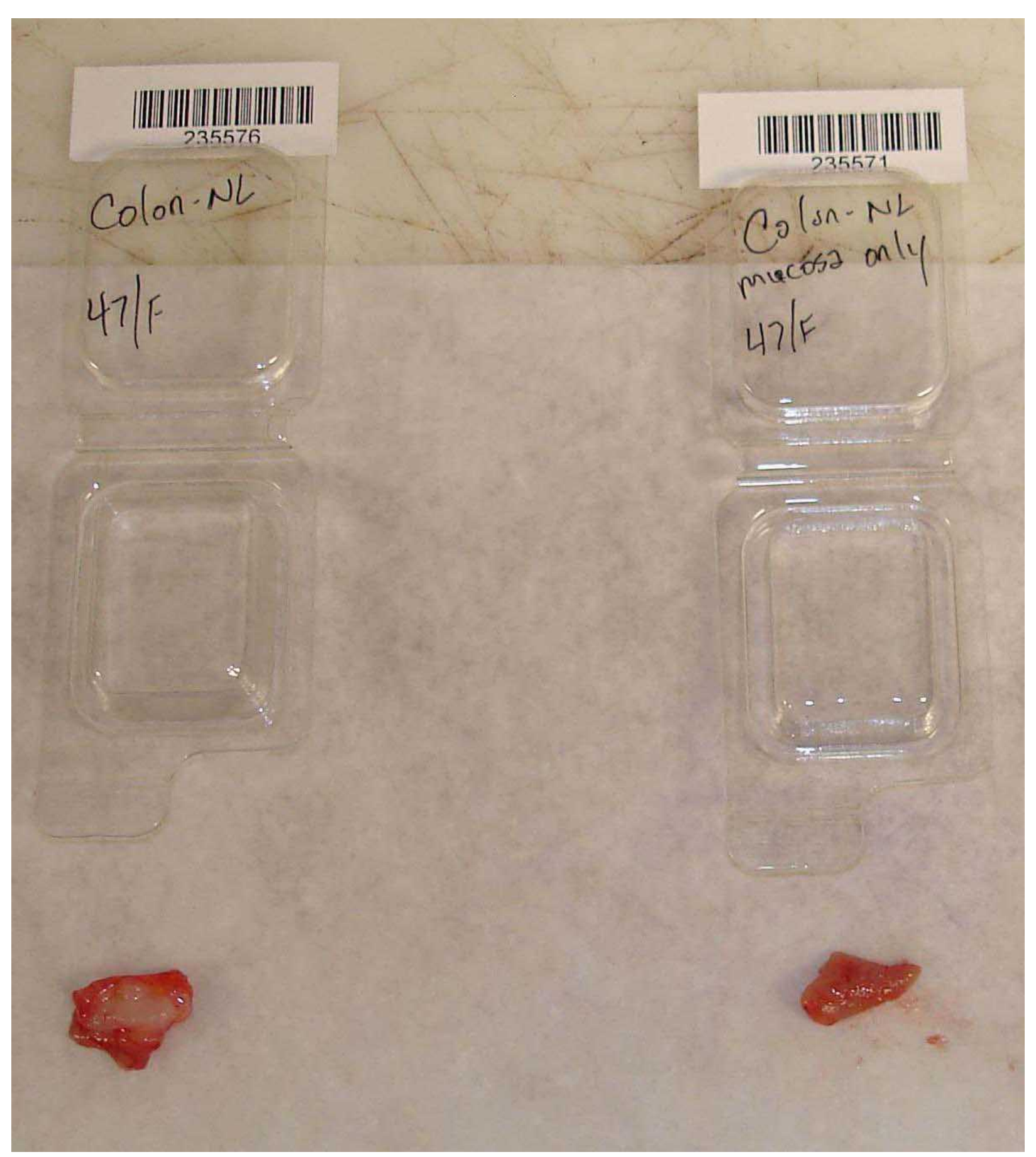

Figure 6. Labeled clamshells for a full-cut section (left) and a mucosa-only section (right).

10 Paraffin block samples should be cut in long, thin (less than $0.5 \mathrm{~cm}$-thick) strips, in a manner as to show both the mucosa and the muscularis of the colon. 


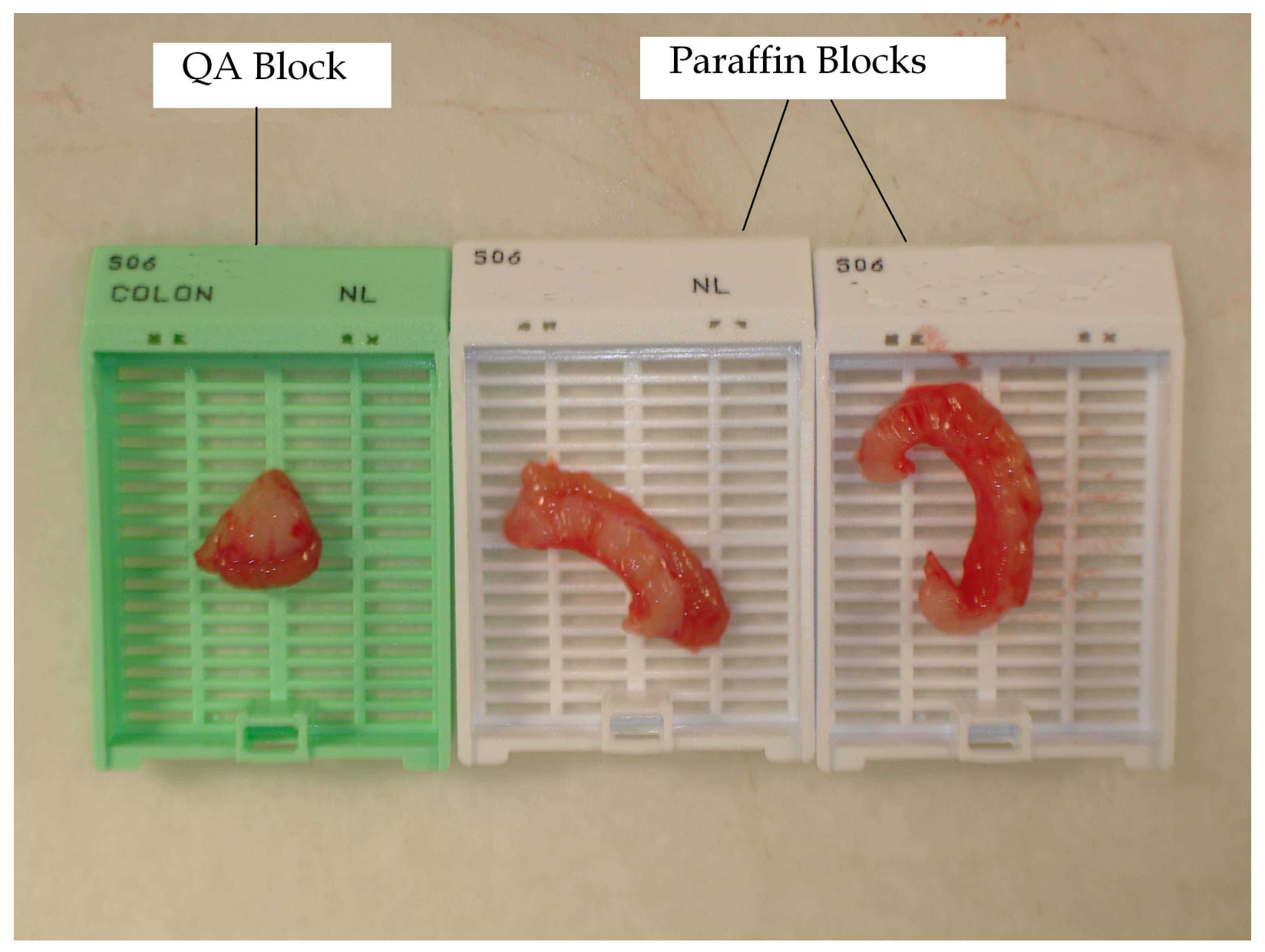

Figure 7. QA block sample (left) and paraffin block samples (right) mounted on cassettes.

11 Similarly, normal colon samples frozen in OCT should display both the mucosa and the muscularis (unless otherwise requested) and follow the general protocol for OCT fixation. 